\title{
Teaching Advanced Legal Research: Philosophy and Context
}

\author{
ROBERT C. BERRING and KATHLEEN VANDEN HEUVEL ${ }^{1}$ \\ Berkeley Law School, University of Califormia, Berkeley, California, USA
}

\begin{abstract}
Is there a philosophy that grounds the teaching of advanced legal research (ALR)? Can a coherent identity be found? The authors draw upon the experience of twenty-five years of teaching ALR to large numbers of students to puzzle this question out. Are we teaching a mechanical skill? Are we offering a course in jurisprudence? Are we simply forcing the students to teach themselves? Has the information revolution changed the whole enterprise? Basing the discussion on the context of legal information, the students, and the law, the authors try to find an answer to these fundamental questions.
\end{abstract}

KEYWORDS teaching legal research, teaching, advanced legal research

\section{THE SETUP}

Writing an article that sets forth a philosophy of teaching Advanced Legal Research (ALR) is a presumptuous exercise. Articulating a philosophy of law librarianship itself has been enough of a challenge. ${ }^{2}$ At least the field of law librarianship has the ethos of a profession with its own professional association that grapples with standards and issues of identity. While there is a rich literature about teaching legal research, complete with a healthy subset of writings about teaching ALR, ${ }^{3}$ there is no developed professional cohort. There is no center to the enterprise.

Each person who offers a course in ALR may have her own ideas and concepts as to what she is doing. In this age of empirical research, we would not presume to venture a guess as to what others think they are doing when they teach an ALR course without the use of a well-designed survey instrument. (Trust us, we do not intend to create one, but would

Address correspondence to Robert C. Berring, Berkeley Law School, University of California, Berkeley, CA 94720-7200. E-mail: berring@law.berkeley.edu 
love to see it done). But our experience tells us that ALR courses take many forms. One of the weaknesses of the field of teaching legal research has been the failure to identify an intellectual structure for it. Courses sprang up to meet a growing need, often on an ad hoc basis. Some focus on special topics; some center on Boolean skills; some are tied to other parts of the curriculum. Viewed by an outsider, there is no unifying thread. To borrow a quotation from Gertrude Stein, there is no there there. ${ }^{4}$

Part of this problem is rooted in the fact that ALR is usually identified on the law school curriculum as a skills course. At top tier law schools, skills courses are at the intellectual margin. 5 They are seldom taught by regular faculty members; in fact, most faculty members at the prestigious law schools lack the real-world expertise to teach them. Skills courses do not lead to the production of academic law review articles, which is the coin of the realm in the world of legal education. Though we think that the ground will soon shift, for now publishing abstract, heavily footnoted pieces in academic law reviews is the path to promotion and status for faculty in the best law schools. While skills courses can be central to the experience of law students, they seldom appear on the radar of the tenure-track faculty.

Given this state of affairs, most observers would contend that a course in ALR has never needed a philosophy. Besides, what could be philosophical about doing research? The answer is, of course, that teaching ALR can be the most deeply philosophical of endeavors. Our approach to a philosophy of ALR parallels the pedagogy that we employ when teaching it. That is the course that we will follow in this article. A bit of perspective on the relation of legal information to ALR will be the start. Then we will reflect on the way the world was, the way the world is, and what the world may be. Following that, we will provide some functional descriptions of what we do and why we do it. Somewhere in there, a philosophy will emerge.

\section{LEGAL INFORMATION AND ALR}

Legal information, its classification, and forms of retrieval are at the heart of legal thinking. Legal information informs legal structure. It dictates how law students, law professors, and lawyers think. Understanding legal information can only be accomplished by learning how to use it. Legal research connects legal information to its user. It is not just a process; the researcher is not just performing an action. In carrying out legal research, one brings legal information to life. Legal research is not just a vehicle for gathering data. The way research is done profoundly affects the information itself. Anyone who understands the inner structure of the soul of legal information understands the workings of the substantive law.

We have been teaching ALR at Berkeley for 23 years. One of the reasons that we started a course in ALR was because it was frightening to us to 
realize how little most law school graduates knew about the materials that were the basic tools of their profession. Contrary to what most law students thought (that is if they thought about it at all), the forms in which legal information appeared were not divinely ordained or historical inevitabilities. They resulted from editorial choices, market forces, and social pressures, translated through the life cycle of profit-making enterprises. When we began teaching ALR, there were long-standing referents in the process of legal research. Everyone used the same set of tools; the cognitive authority of legal research was mapped out. It had been mapped out for so long that no one even noticed it any longer. This well-established galaxy of legal sources made life easier, but it also made many researchers uncritical consumers. One of the reasons that top tier schools tolerated horrendous first-year legal research programs was that the pathways for the researcher were so well worn that it was assumed that everyone would just "catch on."

\section{THE WORLD WHEN WE STARTED}

Take the old paper sets of Shepard's Citators, in the days before KeyCite as an example. Everyone used Shepard's Citators to ascertain the validity of a case. Getting students to use the paper Shepard's correctly was a challenge in itself, but our goal was to make the student see $\boldsymbol{w} \boldsymbol{h} \boldsymbol{y}$ everyone used Shepard's and how to make the best use of it. Our goal was to prevent the student from just blindly Shepardizing his case; we wanted him to understand how the citator was assembled, to recognize what the superscript letters and numbers meant, to question what algorithm the Shepard's editors used to produce the tool. (Of course, we would not have used the word algorithm then). One of our mantras has always been, "Use what they give you." Understand the tool. The folks at Shepard's Citators have built in special features that are designed to assist you. Use those features.

Shepard's was not alone. It was part of a fixed universe of tools. We struggled to help our students understand the blueprints for this world of legal information. Our mission was to wake them up, to shake them out of their comfortable assumptions, and to compel them to take research seriously. ${ }^{7}$ It was a worthy quest, one we enjoyed. But the tectonic plates of legal information shifted. As the paper culture in which we had grown up began to fade away, the problems changed. The students changed. The tools changed. ALR changed too.

Over the past decade, most of the time-honored sources of information have been swept away or deeply changed by the information revolution. In 2008 , teaching ALR is not a matter of explaining the soul of long-established tools. The problem today is not the need to wean students from the existing systems or to make them at least see the value of the existing systems. Today we have to work hard to make our students perceive that there are systems at all. The nature of legal authority is up for grabs. 


\section{THE WORLD WE TEACH IN TODAY}

Two things have dramatically changed in teaching ALR. The first is the students. The second is the information.

The law student of 1983, that person who used the deeply rooted paper system, is quite different from her counterpart of today. The law student of 2008 is a practiced user of Google and Wikipedia. They communicate via text messaging and Facebook. They own an iPhone that allows them to download videos directly from the Internet. They expect to type a search term into a box and get a result. Many are loath to use indices at all. The idea of a two-step look-up as a part of the research process is an anathema to them. Hyperlinks are an inalienable right.

None of the preceding paragraph is written with a fist shaken in anger at the sky. Resenting change is a fool's errand. That paragraph simply describes the way things are in 2008. The student of 1983 had grown up using libraries and books. He had a deep understanding of how the print culture worked, even if he did not know that he did. Even if he would use a library catalog only when in extremis, he could do it if pressed. For many students in our 2008 ALR class, the utility of a library catalog has to be established through logical argument. Nor do we claim that our logical argument always prevails. These students live in a different world. ${ }^{8}$ Anyone who has shown the online version of the Index to Legal Periodicals to a law student and who has seen the look of befuddlement come over her face when she is told that the full text of each indexed article is not linked to its citation, knows whereof I speak. Whether one admires or fears the law student of 2008, one cannot change her.

It is not just the law students that have changed. The whole field of legal information is shifting. We do not just refer to the format in which the information is used. The very nature of the information itself is changing. Today's Supreme Court debates what materials may be cited as binding. Do legislative histories count? ${ }^{9}$ What about international and foreign law? ${ }^{10}$ The Courts are grappling with the true nature of precedent as the very question of what judicial authority undergoes analysis. ${ }^{11}$ The role of legislative materials and how they relate to Presidential power is festering at the federal level. The role and authority of administrative materials is shifting with the change in formats brought on by the omnipresence of laptops and the Internet. As individual administrative agencies experiment with their own Web sites and forms of information distribution, the old templates for publication are gone. These questions of what constitutes the law and legal authority are not new, but they are getting more central each day.

The old paper sets stagger on as mortally wounded dinosaurs. But no one pays them much mind any longer. Reality lies in Lexis and Westlaw; searching grows from the roots of Google. New for-profit players like Bloomberg nibble at the edges. Heroic altruistic efforts like Jurist and the 
venerable Legal Information Institute try to offer an alternative. As Lexis and Westlaw have been bought up and conflated with other information products, it is hard to say what the legal research landscape will look like in 2010, let alone 2018. Ten years down the road is a lifetime. We view our role as teachers of ALR to prepare the students for whatever happens down that road. We tell our students that each of them will be an important consumer of legal information. ALR is about training in critical thinking about information. We are not simply instructing them in how to carry out legal research-we are trying to assist them to become a generation that will demand high-quality legal information. A good deal is at stake.

There was a need for an underlying philosophy for ALR in the time of paper information. Today the need is even more acute. Rather than setting forth an abstract set of principles, we have decided that the best way to set out our philosophy of teaching ALR in the wild days of 2008 is to set our ideas in the terms that we present it to our students. We urge them to see legal information and the process of legal research in terms of context. The pedagogy of Paolo Freire has always influenced us. ${ }^{12}$ Freire would say that one does not transfer bits of knowledge, one teaches a process of thinking and discovery. When it works, the students learn with us, and the teaching is an exciting process. That is how we will present it here.

\section{CONTEXT 1.0}

When teaching ALR, it is crucial to provide the context of the legal information that is discussed. Some term this a functional approach to legal research. Our premise is that rather than instructing the student in how to find a particular piece of information, we offer the student an understanding of the information itself. This idea was rooted in the world of paper, when we wanted students to understand what to do if a familiar book was off the shelf. It is even more important today.

For example, when teaching about carrying out research using judicial decisions, it is vital to make clear how judicial opinions are produced, how they come to be written and distributed. The opinion of the judge does not emerge fully formed from the heavens. It is the product of a creative process, a process imbued with editorial and intellectual, as well as commercial and mechanical, elements. The judge reacts to the briefs of counsel, argues with other judges on the panel, responds to the record from below, and may have a clerk author the actual opinion. The judge decides if the opinion should be published so that it enters into the stream of precedent. Publishers, both official and commercial, add editorial value to the opinion via a syllabus, headnotes, and a research system. If the student can see this process of creation, she can deal with the information that is part of it, no matter how it is formatted. She can also be prepared for the changes in the mix of 
information that may come. The only thing that we are sure of is that change will come.

One way we attempt to get the student to work through these ideas is by means of an exercise where we ask the students to construct the perfect tool for researching a judicial opinion. On a good day, when we push and the classroom comes alive, the students come to see the value of trial court proceedings, discovery materials, and briefs as leading to the opinion. They can also see the utility of citators, commentary, law review articles, expertise from practice, and connections with statutes, regulations, and nonlegal sources leading from the opinion. The judicial opinion is not just a static bit of precedent, it is the center of an information universe. It can be sliced and diced.

We perform an exercise where an opinion moves from the judge's idea, through a clerk's draft, through a judicial conference, to the Thomson Company, through the editing, headnoting, and digesting system, into the Westlaw system, complete with hooks and links. Now the student can see the opinion as one element in an information stream. What she sees on her Westlaw screen or on the printed page is just one step in a process.

If the student comes away with an understanding of how the information is generated and how the form of the information that she sees is produced, then she can handle format changes and new media. The form of the information is not determinative. It is the information itself that matters. Functional understanding of legal information is the start.

This concept is equally important in dealing with statutory material and administrative rules and regulations. Due to the strange structure of legal education, many law students have very little knowledge of these sources. In a sense, this makes it easier to discuss the concepts with them. We do not have to overcome sloppy research habits; we begin with a blank slate. But the same rules apply. We take as an example a piece of enacted legislation, in recent years the U.S.A. Patriot Act. We then work through each step in the legislative process. It is worth noting that many of our highly intelligent second- and third-year law students have either never learned, or have forgotten, the basic high school civics lessons in how a bill becomes law. Step-by-step review of the law-making process, using the Patriot Act, is necessary. In the fall of 2008, we queried our class of 70 as to how many knew what the Statutes at Large might be. Five responded that they knew. This was a salutary reminder of the real state of law school research skills. One of the tricks to teaching ALR over an extended period of time is the need to remember how much the students do not know. We sometimes chuckle at the fact that the course is titled "Advanced Legal Research." Isn't reviewing how a bill becomes law the most basic of legal research tasks? We are teaching them an advanced method of understanding the materials, but you need a foundation before you can build. One can never forget the basics. 
When examining a piece of legislation, the student should see the evolution of documents and commentary that lead to the passage of a new law. A textured understanding of legislative history can assist the student in understanding both the realities of statutory research and the best way to find sources. We do not just present a stack of documents-we show the students tools like CQ Weekly, Roll Call, and the National Journal. We want them to see the context of how the law is passed. How is it that a statute comes to be codified? How is an annotated code constructed? How does all of this tie into the process of amendment?

The student with a grasp of this information stream understands legislative materials, and she can put it in context. She comprehends how the world of legislation works. This functional approach will serve her well.

\section{CONTEXT 2.0}

Students tend to view ALR as an exercise in acquiring and practicing a skill. They are not wrong. We do teach a skill. But we understand that legal research consists of much more than knowing what database to use or what search engine to employ. We want the students to see the information in its intellectual context. The jurisprudential influence of legal information lies at the center of this enterprise.

If the context of legal information is blended into the story of the development of the common law, learning about legal research becomes an exercise in learning about the internal structure of the law itself. Many students approach legal research with the idea that it will be little more than advanced Lexis and Westlaw training. By placing legal information into the frame of the development of American law, the course can be elevated for them. These roots in legal history and jurisprudence are not simply tacked on to the course; they form part of its core. What are the Restatements? Why are law reviews so important? What accounted for the death of the monumental treatise? Why do people still care about the Key Number System? What does the doctrine of precedent really mean? Scholars from Holmes to A.W.B. Simpson have seen the central role of legal information. ${ }^{13}$ The law student of 2008 should know that the centrality of legal information is not new. Is the use of legislative history in arguing a case legitimate? These are all important questions. Weaving each of them into a tapestry of intellectual legitimacy can give the student a framework to hang the research concepts on.

\section{ASSIGNMENTS}

Some elements of carrying out high-quality legal research involve the careful development of skill and judgment. They cannot be explained; they must be learned through experience. No matter how clearly we present the 
information on how to perform a research task, unless the student does it herself, the skill will not take hold. For this reason, we have concentrated our research training efforts on second-and third-year law students via the course in ALR. Most first-year law students do not have enough context to apply the skills that they learn in research and writing. In any case, most of those classes now emphasize writing skills. But even if research was a focus, the first-year law student, immersed in the classic first-year curriculum, has no way to employ the new skills. ${ }^{14}$ The second-year student has much more background and may well have the added incentive of a harrowing summer employment experience during which she was asked to find a recent letter ruling of the Internal Revenue Service or to do a quick legislative history of a newly enacted statute and had no idea how to proceed.

The motivated student with sufficient background can, with our help, teach herself how to do legal research. This is the tricky bit of the way that we conceive ALR. There is only so much the instructor can do before the limits of time and energy intrude. If we want to teach classes of 75 , and we do, we cannot offer one-on-one tutoring. The student must be required to use the new skills in a realistic environment. To this end, we assign openended questions which require the students to do real-world research. Put simply, they teach themselves. We grade the assignments and return each one before the next one is due. To make this system work, we must grade the assignments with dispatch. If the assignments that we return are to be of any use, we must write comments on each one. Since we use four problem sets each semester, we are required to invest considerable time in grading and commenting on student work. Using teaching assistants does not work for us. Each of us, and there are three of us who team teach the course, must commit to reading and commenting on one question on each assignment. It is not a simple regimen for the instructors, but we have found no other way to accomplish our goal. Until we can devise some way to leverage our efforts, extensive investment of time and energy is required. Sweat equity is a component in our philosophy of teaching ALR.

\section{CONCLUSION}

Our philosophy of teaching ALR does not admit to a simple summary. However we put it will be both too grandiose and too simplistic. It is one part information theory, one part jurisprudence, five parts critical thinking, and fifty parts student-generated learning. The course is odd from the start because we recognize that we are not as deft at using many of the online search engines and databases that we discuss as our students are. But we want them to be more than nimble-we want them to understand what they are doing and the nature of the information with which they are working. They are the future. Decisions about the quality and integrity of legal information will 
be made in the coming decade. Those decisions will not be made by us; they will be made by our students. If we can make them critical judges of the new formats and search engines (and whatever currently inconceivable things that are to come), if we can make them demand more than just speed and ease of use, we will have done our job.

\section{NOTES}

1. The royal "we" is used throughout this article. Bob taught the ALR course for a few years before Kathleen who, after having taken it as a student while getting her J.D., joined him, but we are no longer able to disentangle who came up with what, so the "we" is a convenient choice. Michael Levy is the third part of our teaching team in ALR and is the one who has kept our heads above water concerning issues of technology. His ideas are blended into what is said in this article, but he bears no responsibility for our errors or pomposity.

2. The most famous attempt was that of Professor Morris Cohen in his piece on the President's Page column of the Law Library Journal. It is worth noting that this page with its potential for philosophical rumination no longer appears. Morris L. Cohen, Towards a Philosopby of Law Librarianship, 64 L. Lib. J. 1, 1 (1971). Professor Richard Danner has made notable contribution in this field. See e.g. Richard A. Danner, Contemporary and Future Directions in American Legal Research: Responding to the Threat of the Available, 31 Intl. J. Leg. Info. 179 (2003).

3. For an excellent introduction to the literature of the field, see Gallacher, Forty-Two: The Hitchbiker's Guide to Teaching Legal Research to the Google Generation, 39 Akron L. Rev. 191 (2006). The extensive footnotes that are a part of this article offer citations to the complete world of literature on the subject.

4. Ms. Stein's famous quip, made in her classic Everybody's Autobiography (1937, reprinted Exact Change 2004), describes what she found when she visited her childhood home in Oakland, California.

5. For the past several years, the Registrar at Berkeley Law School, when dividing up course offerings by subject and type, placed ALR into a category called "Miscellaneous." The only other course so listed is an ungraded course formerly taught by the Assistant Dean of Students called "Spanish for Lawyers."

6. When Bob went to Harvard Law School to work in 1978, legal research instruction for first-year law students was entirely in the hands of the Board of Student Advisors, a student-run group. Since no one had trained the Board of Student Advisors in how to carry out legal research, and no one on the Harvard Faculty cared, training was primitive at best.

7. The Commando Legal Research video series grew out of these years. In the world of paper, where everything was taken as a given, sometimes one had to wave a rubber chicken to keep the students engaged.

8. John Palfrey \& Urs Gasser, Born Digital (Basic Books 2008) is a very readable description of the student of 2008. Authored by Professor John Palfrey, a cyberlaw expert who has been recently appointed director of the Harvard Law Library, the book is not only a fine source, it is a lovely irony that its author is head of what may be the world's greatest law library.

9. For an informed discussion of the differing opinions of Supreme Court Justices on the use of legislative history, check the Concurring Opinion blog, available at http://www.concurringopinions. com/archives/2007/11/early_reflectio.html.

10. A fine discussion of Justice Scalia's opinions on the use of foreign law by the Supreme Court can be found at the Opiono Juris, the highly regarded blog, available at http://lawofnations.blogspot. com/2006/02/justice-scalia-on-foreign-law-and.html.

11. Two brilliant expositions of the problem of precedent can be found by reading Anastosoff $v$. United States, 223 F.3d 898, vacated as moot on rehearing en banc (8th Cir. 2000) and Hart v. Massinari, 266 F.3d 1165 (9th Cir. 2001). There is no precedential value here, but there is wonderful discussion of the nature of precedent.

12. Paolo Freire, Pedagogy of the Oppressed, (Myra Bergman Ramos trans., Continuum 2000) has informed our teaching for years. "Authentic education is not carried on for 'A' by 'B' or by 'A' about 'B,' 
but rather by 'A' with 'B,'..." p. 82. It is a wonderfully coherent way to think about the entire first year of law school education.

13. A.W.B. Simpson, The Rise and Fall of the Legal Treatise: Legal Principles and the Forms of Legal Literature, 48 U. Chi. L. Rev. (1981) is an elegant statement of the interaction of legal publishing and legal principles. For elegant prose in the service of law books consider this passage: "The means of the study (of law) are a body of reports, of treatises, and of statutes, in this country... these sibylline leaves are gathered the scattered prophecies of the past..." Holmes, The Path of the Law (Yale electronic publication 1897, reprinted Thomson Gale 2004) This beautiful essay has been reprinted many times. The easiest place to find this passage is in Project Gutenberg, available at http://www.gutenberg.org/catalog/world/readfile?fk_files=223748. We are quoting from the second paragraph of the essay. Only Holmes could use the word sibylline.

14. The argument about when and how to teach legal research led us into an exchange of views with Christopher and Jill Robinson Wren. See Christopher G. Wren \& Jill Robinson Wren, The Teaching of Legal Research 80 L. Lib. J. 7 (1988); Robert C. Berring \& Kathleen Vanden Heuvel, Legal Research: Should Students Learn It or Wing It?, 81 L. Lib. J. 431 (1989); Christopher G. Wren \& Jill Robinson Wren, Reviving Legal Research: A Reply to Berring and Vanden Heuvel, 82 L. Lib. J. 463 (1990); Robert C. Berring \& Kathleen Vanden Heuvel, Legal Research: A Final Response, 82 L. Lib. J. 495 (1990). 